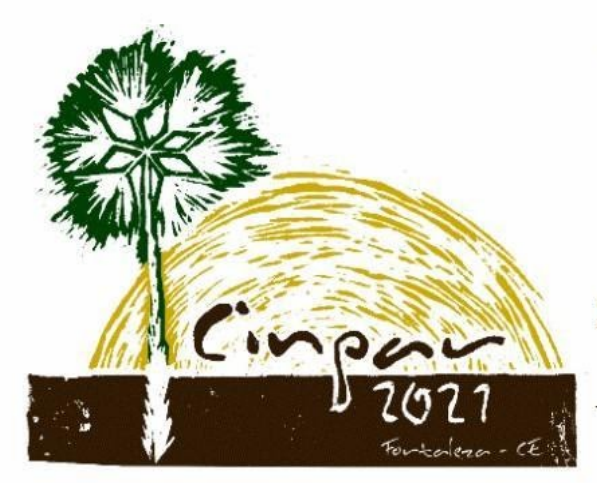

XVII Congresso Internacional sobre Patologia e Reabilitação das Construções

XVII Congreso Internacional sobre Patología y Rehabilitación de las Construcciones

XVII International Conference on Pathology and Constructions Rehabilitation

FORTALEZA (Brasil), 3 a 5 de junho de 2021

https://doi.org/10.4322/CINPAR.2021.135

\title{
Estudo de Caso: Avaliação Patológica e Proposta de Intervenção em Pilares de Concreto Armado
}

\section{Case Study: Pathological Assessment and Proposal for Intervention in Reinforced Concrete Pillars}

\author{
Dyaloisio ARAÚjo ${ }^{1}$, Adiláyne MENDES², Matheus ARAÚJO3, Caio DIÓGENES ${ }^{4}$, Douglas SAMPAIO ${ }^{5}$, Daniela \\ FERNANDES ${ }^{6}$ \\ ${ }^{1}$ KTEK Soluções de Engenharia, Fortaleza, Brasil, ktekengenharia@gmail.com \\ ${ }^{2}$ Universidade Federal do Ceará, Russas, Brasil, adilaynemendes@gmail.com \\ ${ }^{3}$ Universidade Federal do Ceará, Russas, Brasil, m.rib.araujo@gmail.com \\ ${ }^{4}$ Universidade Federal do Ceará, Russas, Brasil, caiod.silva2@gmail.com \\ ${ }^{5}$ Universidade Federal do Ceará, Russas, Brasil, douglassampaio@alu.ufc.br \\ ${ }^{6}$ Universidade Federal do Ceará, Russas, Brasil, danny.fern@alu.ufc.br
}

Resumo: $O$ estudo das anomalias das edificações surge com grande expressão no mercado atual tanto pela preocupação de minimizar os impactos ambientais quanto pela necessidade de restabelecer os parâmetros de desempenho das edificações. Este trabalho expõe resultados do laudo técnico elaborado a partir da investigação do condomínio em Fortaleza - CE e possui como objetivo identificar as manifestações patológicas, suas causas e explicar as etapas de execução do projeto de reabilitação dessas estruturas, embasando esses processos nas normas técnicas vigentes. Realizou-se o mapeamento de danos no edifício, localizado no centro da capital cearense. Ao analisar o grau de criticidade das manifestações patológicas foi executado o escoramento das estruturas com maior grau de degradação. O diagnóstico sensorial aponta o colapso de armadura longitudinais e transversais e a diminuição da seção de aço por corrosão. $O$ alto índice de vazios do concreto serviu de canal para a manifestação do processo de carbonatação que aliado à umidade, proveniente do colapso do tubo de queda, iniciou a redução do pH do concreto, ocasionando o processo corrosivo. Após essa investigação foi possível determinar a terapia de recuperação estrutural, elaborada para solucionar as causas das anomalias e minimizar os efeitos da corrosão.

Palavras-chave: Elementos estruturais. Recuperação estrutural. Infiltração. Manifestações patológicas.

Abstract: The study of building anomalies arises with great expression in the current market both by the concern to minimize environmental impacts and the need to restore the performance parameters of buildings. This paper presents the results of the technical report prepared from the investigation of the condominium in Fortaleza - CE and aims to identify the pathological manifestations, their causes and explain the steps of the execution of the project of rehabilitation of these structures, basing these processes on current technical standards. The mapping of damage in the building, located in the center of the capital of Ceará, was carried out. By analyzing the degree of criticality of the pathological manifestations, shoring of the structures with the highest degree of degradation was carried out. The sensorial diagnosis points out the collapse of longitudinal and transverse reinforcement and the reduction of the steel section due to corrosion. The high rate of voids in the concrete served as a channel for the manifestation of the carbonation process that, together with the humidity from the collapse of the downpipe, started the reduction of the $\mathrm{pH}$ of the concrete, causing the corrosive process. After this investigation it was possible to determine the structural recovery therapy, designed to solve the causes of the anomalies and minimize the effects of corrosion. 
Keywords: Structural elements. Structural recovery. Infiltration. Pathological manifestations.

\section{Introdução}

O ramo de patologias das construções se caracteriza pelo estudo dos processos de degradação, as causas e as técnicas de reabilitação das estruturas. Além de estudar como esses desgastes interferem na durabilidade das construções. O crescimento do estudo das patologias é muito importante para a manutenção e recuperação das construções tombadas como patrimônio histórico e cultural, conservando importantes obras de grande importância cultural para a sociedade (SOUZA, 1998).

Soeiro e Trancoso (2018) relatam que a escassez de espaços para novas edificações no centro urbanos, indica a necessidade de revitalização de edificações antigas, como o caminho para algumas construtoras. De acordo com Da Silva (2017), as questões ambientais e a geração de resíduos pela construção civil ocupam, progressivamente, maiores espaços nos debates sobre os problemas dos países.

Segundo o panorama de recursos sólidos da Abrelpe (2020), os resíduos de construção e demolição aumentaram de 33 milhões de toneladas, em 2010, para 44,5 milhões de toneladas, em 2019. A maioria dos resíduos sólidos, no Brasil, é depositada em aterros sanitários, cerca de 43 milhões de toneladas por ano. Entretanto, a parte de resíduos sólidos que não é encaminhada para unidades adequadas cresceu de 25 milhões para 29 milhões de toneladas por ano.

Diante da problemática exposta, o presente trabalho elucida sobre as manifestações patológicas mapeadas em pilares de um condomínio, no centro de Fortaleza, com 26 anos de sua construção. Objetivando demonstrar as manifestações patológicas encontradas no edifício e relatar as técnicas utilizadas para a reabilitação dessas estruturas.

\section{Referencial Teórico}

\subsection{Corrosão de Armaduras}

A corrosão pode ser definida como a interação de um material com o meio ambiente que resulta na degradação do material, podendo ocorrer por ações físicas, químicas, eletroquímicas, ou pela combinação dessas.

Segundo Helene (1993), para a deterioração do aço dois processos podem ocorrer, o da oxidação direta e o da corrosão eletroquímica. Esse último tendo grande importância na degradação das armaduras. A oxidação direta ocorre quando o os átomos do aço reagem diretamente com o oxigênio, com a formação de um filme uniforme de óxido de ferro. Esse processo corrosivo em temperaturas ambiente é lento.

O processo corrosivo de natureza eletroquímica é resultado da formação de pilhas de corrosão, em meio aquoso, que funciona como eletrólito. Diferentemente da oxidação direta, esse processo não é uniforme pois a dissolução do aço ocorre nas regiões anódicas, enquanto os elétrons movem-se para a região catódica (HELENE, 1993).

Possan (2010) ilustra o processo de corrosão na figura a seguir. 


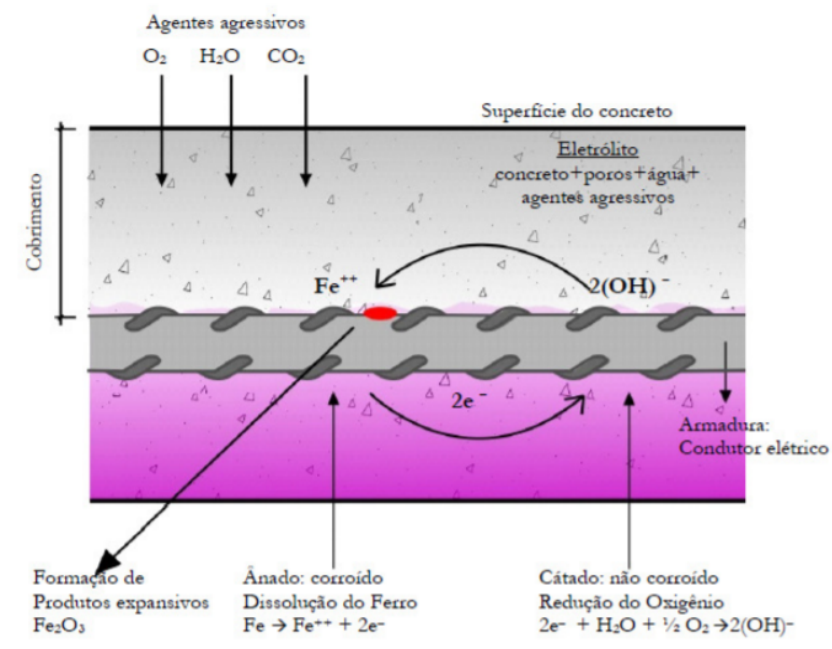

Figura 1 - Processo de Corrosão. Fonte: POSSAN, 2010.

O processo corrosivo do aço no concreto pode ser classificado como generalizada, quando ocorre em toda a região da barra de forma superficial, e como localizada, quando relacionada a despassivação pontual resultado da ação de cloretos ou fissuras e se aprofunda rapidamente na barra. (SABINO, 2014).

A conversão do aço em ferrugem, quando íons cloreto estão presentes, é um processo expansivo e somente ocorre quando existe eletrólito, diferença de potencial e oxigênio. Segundo Mehta e Monteiro (2008), esse aumento no volume é a principal causa para fissuração do concreto.

Em alguns casos, além da fissuração, esse processo pode ocasionar a degradação do concreto e expor a barra de aço ao ambiente, o que acelera o processo corrosivo. Ademais a barra de aço sofre redução da seção transversal, diminuindo resistência e ductilidade (SABINO, 2014).

\subsection{Carbonatação do Concreto}

A carbonatação do concreto é uma reação físico-química entre o gás carbônico $\left(\mathrm{CO}_{2}\right)$ e o hidróxido de cálcio $\left(\mathrm{Ca}(\mathrm{OH})_{2}\right)$, presente no concreto, cujo produto é o carbonato de cálcio $\left(\mathrm{CaCO}_{3}\right)$. Esse processo reduz a alcalinidade do concreto e altera as condições de estabilidade química da película passivadora, fina camada de óxido estável e aderente. O processo corrosivo é iniciado quando essa camada de proteção é destruída pela penetração de cloretos ou pela redução do $\mathrm{pH}$ do concreto para valores inferiores a 9 (FERREIRA, 2013).

Segundo Andrade (1992), como o CaCO3, produto da carbonatação, preenche os poros superficiais, pois é mais volumoso, o concreto está constantemente úmido, devido a diferença de velocidade entre a absorção e a liberação de água. Na figura a seguir, Possan (2010) ilustra o avanço da carbonatação e a alteração do pH ao longo do tempo.

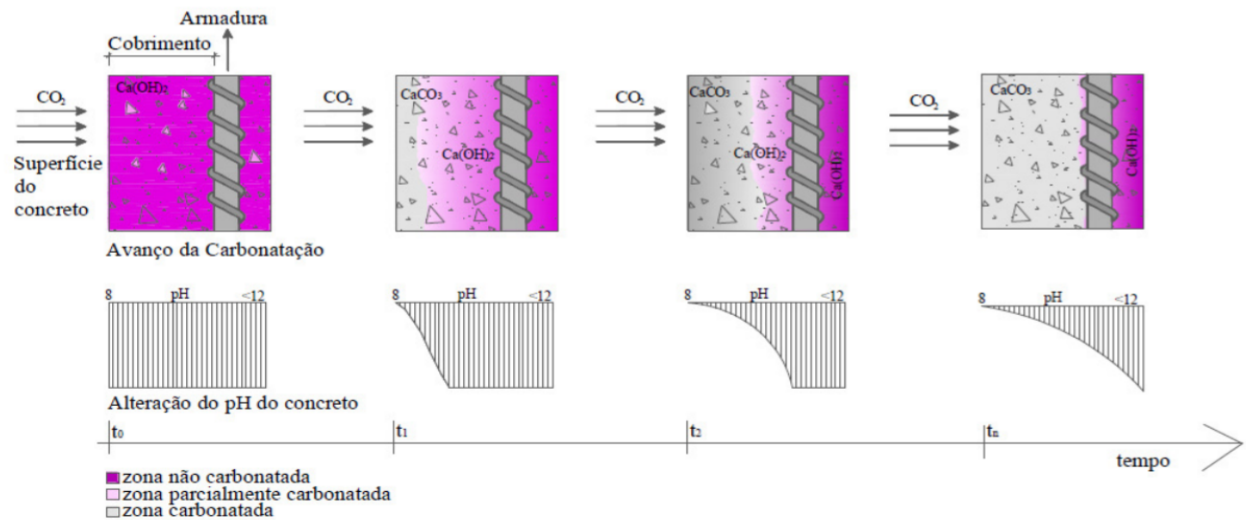

Figura 2 - Avanço da Carbonatação. Fonte: POSSAN, 2010. 


\subsubsection{Fatores que influenciam a carbonatação}

\subsubsection{Meio Ambiente}

Para que o processo de carbonatação ocorra é necessária uma concentração de $\mathrm{CO}_{2}$ no ambiente, proveniente, principalmente, dos processos industriais que utilizam combustíveis fósseis e da exaustão de veículos motorizados (PAULETTI, 2004).

Cascudo (2011) reforça que ambientes como garagem normalmente possuem carbonatação mais intensa do que demais áreas de um edifício. Isso ocorre devido a baixa ventilação desses locais, resultando em maiores concentrações de $\mathrm{CO}_{2}$ em relação às outras áreas do edifício.

Segundo Pauletti (2004), caso a umidade relativa seja inferior a 40\% não haverá água suficiente nos poros para a dissolução dos compostos hidratados. Ao mesmo tempo que se os poros estiverem saturados, cheios de água, o processo de difusão de $\mathrm{CO}_{2}$ é dificultado, ficando a carbonatação mais lenta. Observa-se a carbonatação máxima em uma faixa de umidade relativa de 40 a $85 \%$.

\subsubsection{Concreto}

Segundo Cascudo (2011), características relacionadas à porosidade do concreto são determinantes para a proteção deste ao processo de carbonatação. Com relação às adições no concreto, Helene (1993) explica que, de maneira geral, reduzem a permeabilidade e aumentam a resistência do concreto. Em contrapartida, há uma maior concentração de $\mathrm{Ca}(\mathrm{OH})_{2}$, aumentando a velocidade de carbonatação.

Pauletti (2004) complementa dizendo que se considerarmos apenas a carbonatação, concretos com adição tendem a carbonatar mais. Porém, com relação a corrosão causada por carbonatação a diminuição da permeabilidade possui impacto positivo, dificultando o processo corrosivo.

A cura do concreto é um processo muito importante pois, se bem executado nas primeiras horas (entre 30 minutos e 6 horas), evita a retração plástica e as fissuras consequentes desse processo. Além de aumentar a hidratação do cimento na superfície, diminuindo sua porosidade (CASCUDO, 2001).

Helene (1993) explica que a profundidade da carbonatação está diretamente relacionada com a cura, pois a hidratação afeta os milímetros superficiais. Cimentos com adições podem diminuir a carbonatação, desde que o processo de cura seja bem executado.

Ainda segundo a autora, a relação água/cimento influencia diretamente na porosidade e permeabilidade do cimento, controlando as propriedades relacionadas a microestrutura do concreto endurecido. Sendo assim, quanto menor essa relação, menor a dimensão dos poros capilares, o que dificulta a difusão do gás carbônico.

\section{Metodologia e resultados}

\subsection{Caracterização do objeto de estudo}

O condomínio com área de $1.164,4 \mathrm{~m}^{2}$, localizado no Centro de Fortaleza, referenciado neste trabalho como condomínio A, com idade aproximada de 26 anos. $O$ edifício com área construída de $421,5 \mathrm{~m}^{2}$ em estrutura concreto armado possui onze pavimentos, sendo o primeiro destinado ao estacionamento, como mostra a Figura 3. 


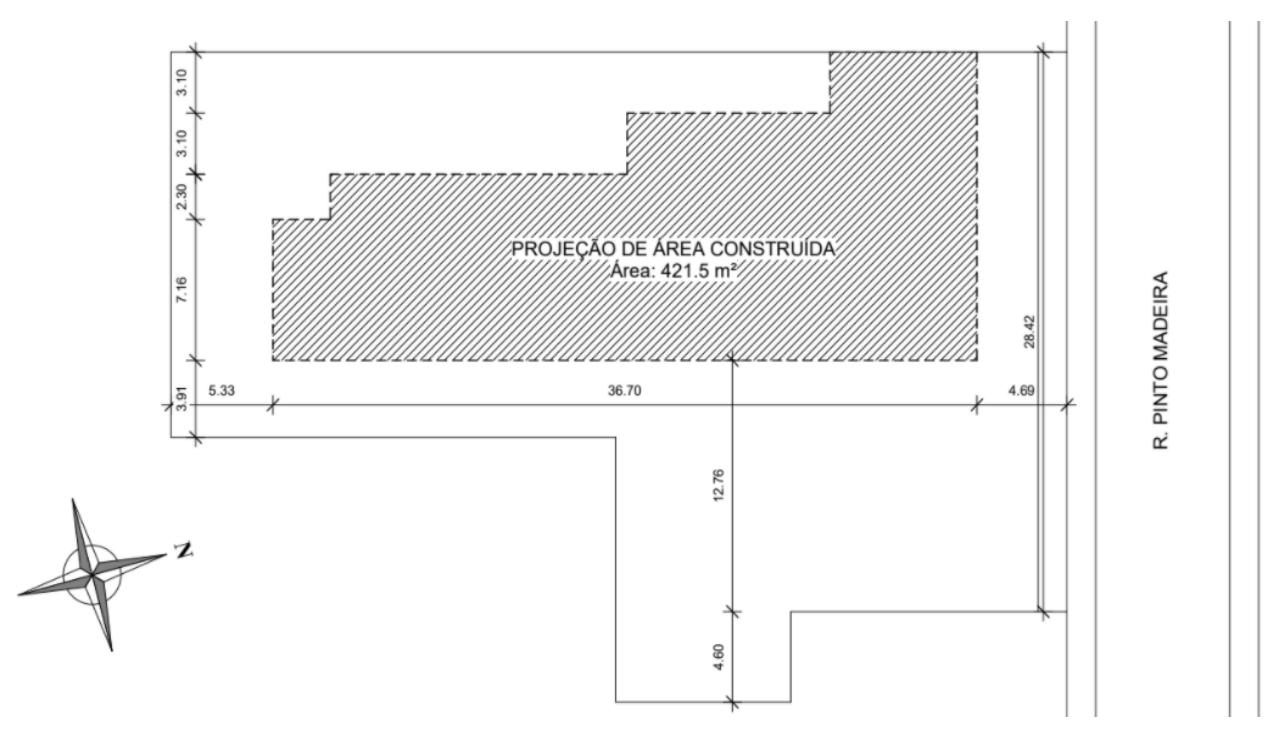

Figura 3 - Planta de locação do edifício. Fonte: Próprio autor.

\subsection{Descrição de etapas realizadas}

Souza e Ripper (1998) falam sobre a necessidade de, após constatar que uma estrutura de concreto armado apresenta problemas, realizar uma vistoria detalhada e cuidadosamente planejada. Desta forma, com o objetivo de identificar e avaliar as manifestações patológicas foi executada uma minuciosa inspeção no imóvel com o intuito de avaliar as anomalias da edificação e detectar as possíveis causas dos processos de deterioração do concreto.

Durante a inspeção do imóvel foram identificadas áreas de concreto deterioradas em 9 (nove) pilares do pavimento térreo, utilizado como garagem, caracterizadas pela presença de fissuras e desplacamentos nas faces destes elementos estruturais. Ainda, foram encontradas infiltrações decorrentes do colapso de tubos de quedas dentro dos shafts, localizados ao lado dos pilares.

Segundo Pauletti (2014), a presença de umidade, como identificada pelas infiltrações encontradas, pode influenciar no processo de carbonatação na dissolução dos componentes hidratados. Cascudo (2011) afirma que em alguns ambientes, como as garagens, este processo se dá de forma mais intensa, devido a deficiência de ventilação e a alta concentração de $\mathrm{CO} 2$. Já o processo de carbonatação está associado à corrosão das armaduras, pois destrói a película passivadora das armaduras, iniciando o processo corrosivo.

Desta forma, as fissuras e desplacamentos encontrados nos pilares podem estar relacionados à expansão do óxido de ferro, decorrente de um processo de corrosão (THOMAZ, 2007). Assim, para identificar o grau de degradação dos elementos estruturais onde foram encontradas as anomalias, foram propostos o apicoamento das áreas degradas para investigação das armaduras. Também foi realizada a escavação de 1 (um) metro da superfície e abaixo da anomalia identificada, para inspecionar o bloco de fundação e aprofundar a análise das manifestações patológicas

A princípio, antes dos procedimentos de reparo das armaduras foram sanadas as infiltrações decorrentes da ruptura do tubo de queda, que contribuíram para o surgimento das manifestações patológicas. Ainda, foi elaborado um projeto de escoras, de acordo com a NBR 15696/2009 nas áreas mais deterioradas para garantir segurança na execução dos procedimentos, tanto os de investigação como os de recuperação. Ainda,

Os pilares que apresentaram manifestações patológicas estão destacados na Figura 4. 


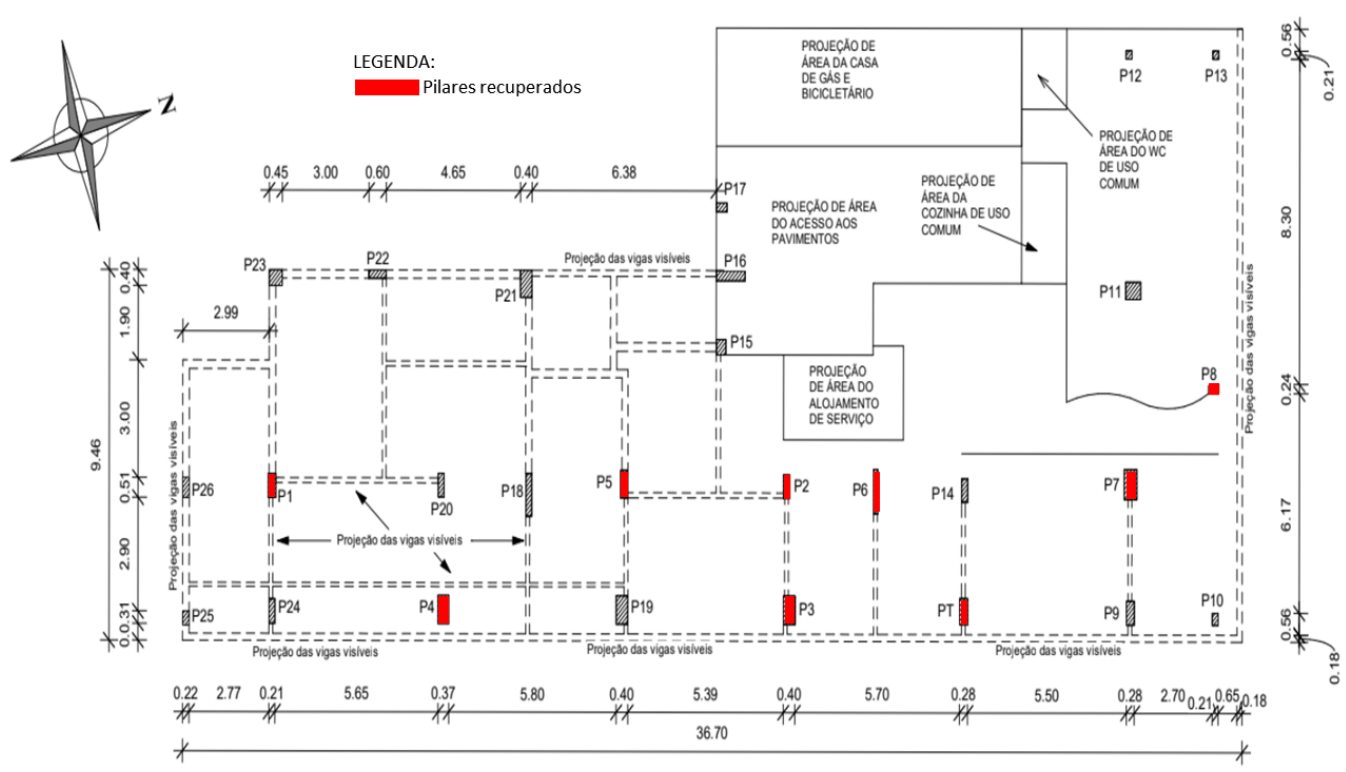

Figura 4 - Mapeamento de pilares. Fonte: Próprio autor.

Thomaz (2007) recomenda realizar o apicoamento do concreto durante o procedimento de reforço do pilar, Executou-se, então, a progressão do processo de degradação da estrutura deteriorada e constatou-se a redução de seção das armaduras longitudinais e transversais, devido à corrosão.

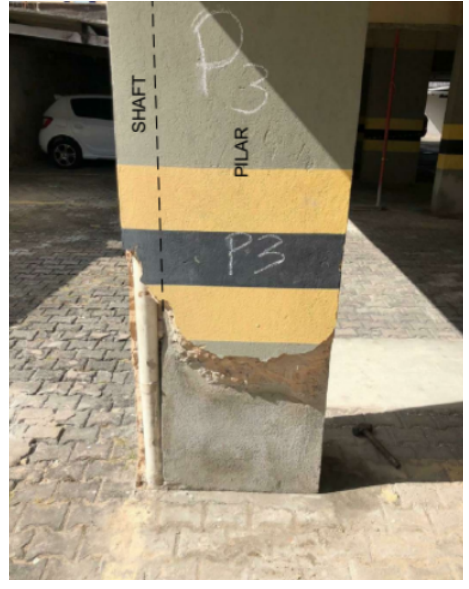

(a)

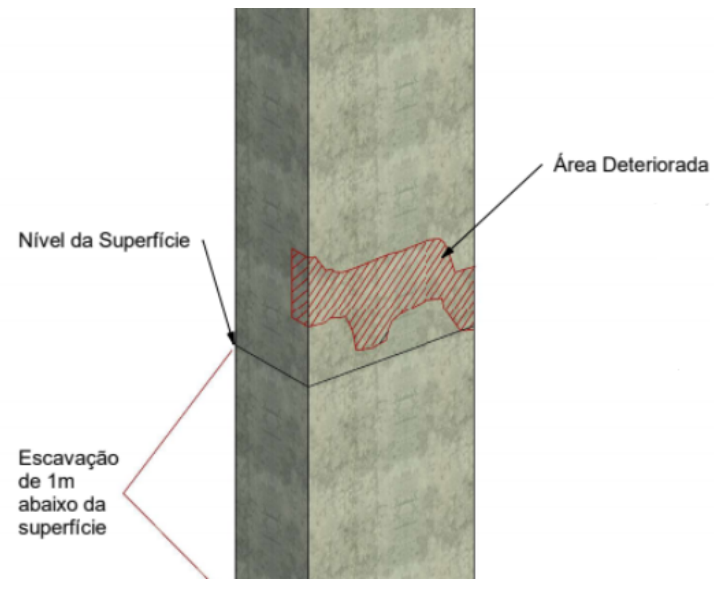

(b)

Figura 5 - Área deteriorada do pilar P3. (a) Fotografia do P3 e (b) Esquema de áreas deterioradas. Fonte: Próprio autor.

Segundo Thomaz (2007), as armaduras devem ser escovadas para remoção de poeiras, para facilitar sua aderência ao concreto. Realizou-se, nas armaduras existentes, a escovação para então serem soldadas às novas armaduras. Sendo que essas substituíram aquelas que apresentaram colapso ou redução de seções. Então, receberam tratamento com neutralizador, para converter as ferrugens em proteção e, 24 (vinte e quatro) horas após esse processo, executou-se a aplicação do anticorrosivo à base de zinco.

Para preparação e aplicação do concreto, de acordo com a NBR 12655/2015, foi utilizado cimento Portland para obras estruturais do tipo CP II F-40, com adição de fíler, e resistência de $40 \mathrm{MPa}$, além disso foi executado um capeamento de três (3) centímetros em toda a peça. Esse último procedimento foi executado com o objetivo de aumentar a cobertura do concreto, garantindo proteção física e química.

Esses procedimentos foram executados nos nove (9) pilares que apresentaram deterioração. 


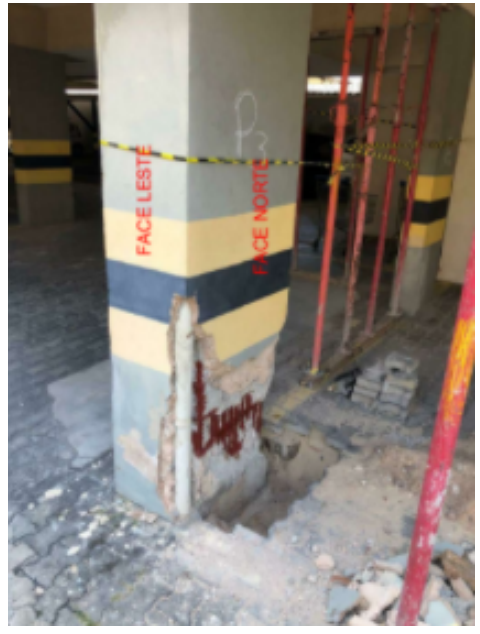

(a)

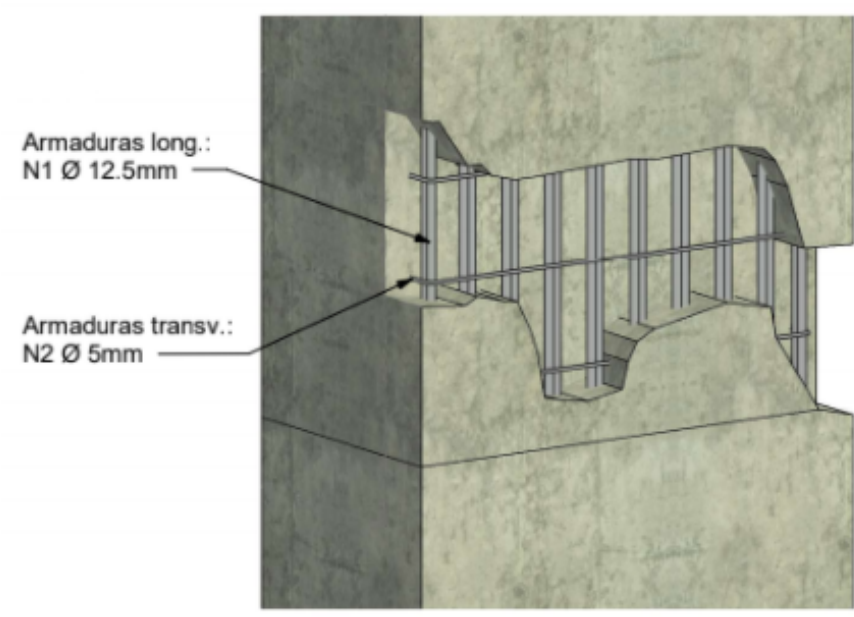

(b)

Figura 4 - Procedimento de recuperação do pilar P3. (a) Execução da escavação (b) Esquema de armaduras longitudinais e transversais Fonte: Próprio autor.

\section{Conclusão}

Segundo Sabino (2014), a alta concentração de $\mathrm{CO}_{2}$ e a presença de umidade colabora com umas das hipóteses de que a corrosão das armaduras seja decorrente do processo de carbonatação do concreto que altera as condições de estabilidade da película passivadora.

Após a investigação predial e mapeamento das manifestações patológicas, constatou-se a existência de corrosão nas armaduras longitudinais e transversais dos pilares da garagem do edifício, que resultou na redução de seções útil e expansão de volume da armadura, resultando no desplacamento do concreto.

Dessa forma, as soluções executadas de reabilitação da estrutura, reparo das tubulações colapsadas, tratamento e substituição das armaduras, bem como capeamento realizado, sanam as causas das anomalias construtivas, devolvendo desempenho à edificação.

\section{Referências bibliográficas}

ABRELPE - ASSOCIAÇÃO BRASILEIRA DAS EMPRESAS DE LIMPEZA PÚBLICA E DE RESÍDUOS ESPECIAIS. Panorama de resíduos sólidos no Brasil. Relatório de 2020. Disponível em:https://abrelpe.org.br/panorama-2020/. Acesso em: março/2021.

ANDRADE, C. Manual para diagnóstico de obras deterioradas por corrosão de armaduras. São Paulo, Pini, 1992.

AQUINO, T. A.; MONTEIRO, E. C. B.; DEMÉTRIO FILHO, A. Z. Inspeção predial no tocante ao sistema estrutural: estudo de caso. Recife, 2017.

ASSOCIAÇÃO BRASILEIRA DE NORMAS TÉCNICAS. NBR 12655: Concreto de cimento Portland - Preparo, controle, recebimento e aceitação - Procedimentos. Rio de Janeiro, 2015.

ASSOCIAÇÃO BRASILEIRA DE NORMAS TÉCNICAS. NBR 15696: Fôrmas e escoramentos para estruturas de concreto - Projeto, dimensionamento e procedimentos executivos. Rio de Janeiro, 2009.

ASSOCIAÇÃO BRASILEIRA DE NORMAS TÉCNICAS. NBR 6118: Projetos de estrutura de concreto Procedimento. Rio de Janeiro, 2014.

CASCUDO, O. e CASAREK, H. Concreto: Ciência e Tecnologia Vol. I. Capítulo 24. IBRACON, 2011.

DA SILVA, Diogo Hilário et al. Construção sustentável na engenharia civil. Caderno de Graduação: Ciências Exatas e Tecnológicas, v. 4, n. 2, p. 89-99. Alagoas, 2017. 
FERREIRA, MURILLO B. Estudo da carbonatação natural de concretos com diferentes adições minerais após 10 anos de exposição. 2013. 197. Dissertação, Pós-Graduação em Geotecnia, Estruturas e Construção Civil, Universidade Federal de Goiás, Goiânia, Goiás.

HELENE, P. R. L. Contribuição ao estudo da corrosão em armaduras de concreto armado. 1993, 213f. Tese (Livre Docência) - Departamento de Engenharia Civil, Escola Politécnica da Universidade de São Paulo, São Paulo, 1993.

MEHTA, P. K; MONTEIRO, P. J. M. Concreto: microestrutura, propriedades e materiais. São Paulo, IBRACON, 2008.

PAULETTI, Cristiane. Análise comparativa de procedimentos para ensaios acelerados de carbonatação. Dissertação (Mestrado em Engenharia) - Curso de Pós-Graduação em Engenharia Civil, Universidade Federal do Rio Grande do Sul, Porto Alegre, 2004.

POSSAN, E. Modelagem da Carbonatação e Precisão de Vida Útil de Estruturas de Concreto em Ambiente Urbano. Tese de doutorado (Doutorado em Engenharia) - Escola de Engenharia Programa de Pós-Graduação em Engenharia Civil, UFRGS, Porto Alegre, 2010.

SABINO, Mariana de Almeida. Avaliação da carbonatação em pilares de concreto armado em garagens: estudo de caso. 2014.

SOEIRO, J. M; TRANCOSO, H. Inspeção e diagnóstico de manifestações patológicas em estruturas de concreto armado: estudo de caso. Revista Construindo, v. 10, n. 01, p. 61-74. Belo Horizonte, 2018.

SOUZA, V. C. M DE; RIPPER, T. Patologia, recuperação e reforço de estruturas de concreto. São Paulo: Pini, 1998.

THOMAZ, E. (2007). Trincas em Edifícios, causas, prevenção e recuperação. IPT. EPUSP/PINI, São Paulo, São Paulo; 2007 